\title{
RELAÇÕES DO DIREITO DO TRABALHO COM OUTRAS DISCIPLINAS NÃO-JURÍDICAS
}

\author{
Sérgio Pinto Martins \\ Professor Titular do Departamento de Direito \\ do Trabalho da Faculdade de Direito da \\ Universidade de São Paulo
}

Resumo:

O trabalho apresenta as relações do Direito do Trabalho com disciplinas nãojurídicas.

Abstract:

This paper presents the relations between Labour Law and other materias.

Unitermos: Relações do Direito do Trabalho.

Introdução

1. Esse trabalho representa a aula sobre o tema relações do Direito do Trabalho com outras disciplinas jurídicas no curso de pós-graduação da Faculdade de Direito da Universidade de São Paulo.

Há grande dificuldade em serem encontrados textos sobre o tema. Alguns são muito curtos, outros em língua estrangeira, outros são textos especializados na matéria em si e não em Direito do Trabalho.

Irei examinar a relação do Direito do Trabalho com a Sociologia, a Economia, a Administração de Empresas, a Contabilidade, a Estatística, a Medicina, a Psicologia e a Filosofia do Trabalho'

Relações Industriais

2. Na Revolução Industrial o trabalho adquire papel fundamental. As normas civis não eram suficientes para regular a questão do trabalho.

1. Agradeço a compilação do matcrial à professora Walküre Lopes Ribciro da Silva, que me forncceu muitos textos, scm os quais o presente trabalho não scria terminado. 
A denominação utilizada é relações industriais ou industrial relations. É originária do século XIX, principalmente da Inglaterra e dos EUA.

Significa a forma de regular as relações entre o capital e o trabalho na indústria.

O presidente americano William Howard Taft propôs a criação de Comissão de Relações Industriais em virtude de protesto popular pela morte de vinte pessoas, em razão de bomba colocada por lideranças sindicais de metalúrgicos no edifício do Los Angeles Times, em 1910.

As relações industriais eram consideradas como o conjunto de relações entre empregadores e empregados, bem como das associações por eles formadas, os meios de negociação e seus conflitos.

A crítica que se faz a tal denominação é que o Direito do Trabalho não se preocupa apenas com as relações industriais, mas com qualquer ramo de atividade em que haja trabalhadores, como no comércio, nos bancos, nas empresas prestadoras de serviços.

Hoje, Direito Industrial é parte do Direito Comercial, que estuda marcas, patentes, invenções etc.

Relação do Direito do Trabalho com outras disciplinas

3. O Direito do Trabalho tem relação com várias outras disciplinas, tanto Ciência sociais, como exatas ou biológicas.

História

4. O Direito do Trabalho não deixa de ser uma realidade histórico-cultural, não admitindo o estudo de quaisquer de suas partes sem que se tenha uma noção de seu desenvolvimento dinâmico no transcurso do tempo.

À luz da História podemos compreender com mais acuidade os problemas atuais. A concepção histórica mostra como foi o desenvolvimento de certa disciplina, além das projeções que podem ser alinhadas com base no que se fez no passado, inclusive no que diz respeito à compreensão dos problemas atuais. Não se pode, portanto, prescindir de seu exame. É impossível ter o exato conhecimento do trabalho sem se proceder a seu exame histórico, pois se verifica suas origens, sua evolução, os aspectos políticos ou econômicos que o influenciaram, de como era organizado e de como ele era disciplinado.

Ao analisar o que pode acontecer no futuro, é preciso estudar e compreender o passado, estudando o que ocorreu no curso do tempo, o progresso da tecnologia. Heráclito 
já dizia: o homem que volta a banhar-se no mesmo rio, nem o rio é o mesmo rio e nem o homem é o mesmo homem. Isso ocorre por que o tempo passa e as coisas não são exatamente iguais como eram, mas precisam ser estudadas para se compreender o futuro. Para fazer um estudo sobre o que pode acontecer no futuro é necessário não perder de vista o passado. Não se pode romper com o passado, desprezando-o. Segundo as lições de Waldemar Ferreira, "nenhum jurista pode dispensar o contingente do passado a fim de bem compreender as instituições juridicas dos dias atuais".

A constatação de várias aspectos históricos pode ajudar a compreender a relação do Direito do Trabalho com outras disciplinas.

\section{Sociologia}

5. A Sociologia vai se preocupar em estudar os fenômenos sociais. Nesse estudo, serão utilizados dados estatísticos, pesquisas de campo etc. Não tem por objetivo a Sociologia a interpretação da norma jurídica.

Irá a Sociologia analisar as sociedades, os conflitos existentes nela, quanto aos fatos sociais que dão origem às questões trabalhistas, os grupos, as classes, as instituições, os processos, os movimentos sociais, que acabam influenciando na formação das leis, principalmente trabalhistas.

A Sociologia se preocupa com o estudo social da empresa, do sindicato, da greve, do emprego, enquanto fatos sociais.

Irá a Sociologia do Trabalho estudar as coletividades humanas formadas pelo trabalho.

Ultimamente há até estudos sobre o ócio (Domenico de Masi).

Obra importante é o "Tratado de Sociologia do Trabalho". de Georges Friedmann e Pierre Naville, da editora Cultrix, de 1962.

Economia

6. A Economia é a ciência que tem por objetivo o estudo da distribuição de riquezas, da produção e do consumo.

O Direito do Trabalho relaciona-se com a Economia a partir do momento em que o Estado intervém no sistema produtivo, estabelece políticas que têm reflexos no nivel de emprego. A relação entre empregado e empregador tem causa econômica. A Economia tem por objetivo primordial o estudo da produção, distribuição e consumo de bens indispensáveis ou úteis à vida coletiva. Os fatos econômicos dão ensejo, porém, 
a modificações na estrutura jurídica. Exemplos são a globalização, o Mercosul, as crises econômicas etc. $O$ governo intervém na economia estabelecendo uma política econômica, uma política salarial, que terão influência na relação de emprego.

Evaristo de Moraes Filho afirma que "pode-se dizer sem receio de errar que nenhum outro ramo do direito vive tão próximo das manifestações econômicas como o Direito do Trabalho. O seu conteúdo é econômico por excelência" Leciona Arion Sayão Romita que "o Direito do Trabalho se propõe realizar o socialmente desejável, mas encontra limitações no economicamente possivel" George Gurvitch afirma que, "nos vários tipos de sociedade, ora é a economia que, ultrapassando a realidade juridica, serve-lhe de fator, ora o direito que, guiando a realidade econômica condiciona-a". Miguel Reale declara que há "uma interação dialética entre o econômico e o jurídico, não sendo possivel reduzir essa relação a nexos causais, nem tampouco a uma relação entre forma e conteúdo" Não há como deixar de reconhecer o impacto dos fenômenos da economia na formulação das regras de Direito. Como assevera, porém, Rudolf Stammler: "se o conteúdo dos atos humanos é econômico, a sua forma é necessariamente jurídica"

O Direito do Trabalho não pode ignorar os fatores macroeconômicos, como a relação entre população e população ativa, as modificações decorrentes da tecnologia, o grau de investimento público ou privado, o grau de consumo, a capacidade de poupança, a distribuição da renda nacional, o nível de emprego, a produtividade, os preços etc.

Após 1946, com o final da Segunda Guerra Mundial, há a consagração do regime de economia de mercado com finalidade social, sendo a busca do pleno emprego um dos objetivos das políticas governamentais. Exemplos dos reflexos da política governamental no Direito do Trabalho são a limitação da jornada de trabalho, que pode influir no volume de produção. Ao se observar certas regras mínimas trabalhistas, até mesmo de segurança e higiene do trabalho, pode ocorrer o aumento dos custos das mercadorias e dos serviços. O mesmo se pode dizer com o aumento do salário mínimo, que, em contrapartida, pode gerar um aumento do poder de compra e de venda de mercadorias e serviços.

$\mathrm{Na}$ verdade, existe uma interação entre o Direito do Trabalho e a Economia. Os fatos econômicos influenciaram a história do Direito do Trabalho, como se verifica com a Revolução Industrial. Entretanto, o Direito do Trabalho também pode influenciar a Economia, como ocorre com determinações legislativas, como de política salarial etc. 
O Direito do Trabalho não faz parte, porém, do Direito Econômico. Este é matéria pluridisciplinar, como afirmam Orlando Gomes e Antunes Varela. O Direito Econômico irá estudar os vários processos econômicos, entre os quais se incluem a terra, o capital e o trabalho no sistema de produção.

O trabalho é visto como elemento de produção. A mão-de-obra é elemento essencial nesse sentido. São também aspectos importantes: o nível de oportunidades de emprego, a mobilidade dos trabalhadores e os efeitos da inflação sobre os salários.

A Economia Social visa proporcionar a elevação do nível de vida das pessoas, mediante a utilização da assistência, da mutualidade, da proteção à mulher e ao menor, o uso adequado da horas de descanso e das férias.

A teoria dos jogos serve para mostrar a tomada de decisões nas negociações coletivas e os resultados que dependam parcialmente das ações de uma das partes.

Empresa é um conceito econômico: é a atividade organizada para a produção de bens e serviços para o mercado visando lucro.

O trabalho, do ponto de vista econômico, é a produção de bens ou serviços para o mercado. É um dos fatores da produção, juntamente com a terra e o capital.

O salário é analisado sob o enfoque da oferta e da procura também para se buscar uma remuneração justa e suficiente. Com base na teoria dos salários e do emprego são observadas as seguintes indagações. Como se determina os níveis e diferenças salariais? Como são afetadas as variações de salários na empresa? O que determina o nivel geral de salários? Em que condições podem os sindicatos influir nos níveis de salários? Qual a relação entre os níveis de salários e preços? Que fatores influenciam o componente salarial da renda nacional?

As políticas públicas ajudam a verificar os problemas do trabalho, de acordo com uma política de trabalho, política salarial e política macroeconômica.

A política salarial não existe no momento. Estabelece o art. 10 da Lei n. 10.192 que os salários e as demais condições referentes ao trabalho continuam a ser fixados e revistos, na respectiva data-base anual, por intermédio da livre negociação coletiva. Essa política vem do tempo do Governo Collor, com a Lei n. 8.030/90, que revogou a Lei n. 7.788/89, que previa o reajuste pelo IPC.

A teoria do mercado de trabalho é apenas uma parte da teoria geral dos mercados. 
Pleno emprego

7. Romita afirma que a expressão pleno emprego tem significado meramente heurístico.

Constitui o pleno emprego uma questão política.

A Constituição portuguesa assegura a todos o direito ao trabalho (art. $58,1)$. O dever de trabalhar é inseparável do direito ao trabalho. Incumbe ao Estado, por meio da aplicação de planos de política econômica e social, garantir o direito ao trabalho, assegurando a execução de políticas de pleno emprego (art. 58, 3, a).

Dispunha o art. 145 da Constituição de 1946 que a ordem econômica era organizada conforme os princípios da justiça social, conciliando a liberdade de iniciativa com a valorização do trabalho humano. O parágrafo único dispunha que a todos seria assegurado trabalho que possibilitasse existência digna, sendo o trabalho obrigação social.

Previa o inciso VI, do art. 160 da Emenda Constitucional n. 1, de 1969, que um dos princípios da ordem econômica e social era "a expansão das oportunidades de emprego produtivo"

O inciso VIII, do art. 170 da Constituição estabelece o princípio de que a ordem econômica busca o pleno emprego. Essa é, contudo, uma regra programática que deve ser complementada pela lei ordinária, não querendo dizer, portanto, que a terceirização é proibida quando implica a diminuição dos postos de trabalho nas empresas, pois é apenas um princípio a ser buscado.

Pleno emprego é a situação em que a demanda de trabalho é igual ou inferior à oferta. Isso significa que todos que desejarem vender sua força de trabalho pelo salário corrente terão condições de obter um emprego. Em termos globais, é possível dizer representa o grau máximo de utilização dos recursos produtivos tanto materiais como humanos dentro de uma economia. Numa economia dinâmica é muito dificil ocorrer a eliminação total do desemprego, pois: atividades como agricultura não ocupam a mesma força continuamente (efeito sazonal); é necessário algum tempo para que as pessoas troquem de emprego, uma vez que ninguém quer viver desempregado; existe uma situação de pleno emprego caso não exceda 3 a 4\% de mão-de-obra desempregada (versão moderna da teoria keynesiana).

A busca do pleno emprego pode até parecer uma condição utópica, inatingivel, mas, na verdade, é uma forma de política econômica adotada pelos governos, com o objetivo de ser atingida.

O objetivo do constituinte parece ser atingir o ideal de Keynes, no sentido de emprego pleno de todos os recursos e fatores da produção. 
Para a OIT, pleno emprego é a ausência de desemprego involuntário ou a existência de trabalho para todos aqueles que desejam trabalhar.

Pleno emprego significa emprego total, emprego para todos que procuram trabalho.

O pleno emprego tem sentido econômico e não jurídico. É uma forma de garantir o direito social ao trabalho (art. $6 .^{\circ}$ da Constituição) ou o primado do trabalho (art. 193 da Lei Magna).

O jurista deve, porém, dar subsídios jurídicos para que os economistas possam estabelecer um sistema voltado para o pleno emprego, como requer a Constituição.

Há relação entre pleno emprego e oferta de trabalhadores. Se aumentar a oferta de trabalhadores sem que haja postos de trabalho, existe desemprego.

O pleno emprego só será conseguido com investimentos, públicos e privados, de forma a gerar postos de trabalho, além do que deve haver redução da taxa de juros.

José Pastore informa que no Brasil, em 1970, para criar um emprego era necessário um investimento de US\$10 mil. Na década de 1980 era preciso US\$ 15 mil. Hoje, são necessários US\$30 mil. Constata-se que há necessidade de muito mais capital para gerar o mesmo posto de trabalho.

Declara José Pastore que "já foi o tempo em que com $1 \%$ de crescimento econômico gerava-se 0,5\% de emprego. Hoje, para gerar esse montante de emprego é preciso crescer mais de $2 \% "$

Para que haja a geração de empregos é preciso crescimento sustentado. No período do "milagre econômico" a taxa de investimento foi de $25 \%$ do PIB, enquanto o crescimento chegou a $10 \%$ ao ano. Atualmente a taxa de investimento é de $17 \%$ do PIB, sendo que o crescimento está em torno de 2 a $3 \%$ ao ano. Para que houvesse a criação de empregos, o PIB teria de crescer entre 6 e $7 \%$ ao ano.

A conquista e a manutenção de um nível de pleno emprego são um importante fator de crescimento econômico acompanhadas da elevação do padrão de vida da população. Os governos podem aplicar uma política de pleno emprego, por meio de recursos fiscais, como incentivos e empreendimentos geradores de emprego e monetários quando ocorre o direcionamento dos créditos e das verbas. Exemplo da crise de 1929, o pleno emprego tornou-se um objetivo nacional de todos os grandes países industrializados e mais especificamente nos EUA com a implantação do New Deal e a aprovação da Lei do Emprego em 1946. 
O governo pode aplicar pleno emprego por meio de recursos fiscais, como incentivos, empreendimentos geradores e monetários, quando ocorre o direcionamento dos créditos.

Keynes assevera que o emprego depende da demanda efetiva por bens e serviços. O desemprego seria causado por uma deficiência da demanda agregada. Só se preocupava com o desemprego funcional. A idéia era acabar com a miséria econômica e seus malefícios.

O. W. Phelps afirma que para manter o pleno emprego deve-se encontrar o montante da renda nacional que produzirá o emprego desejado, tomando-se as providências para que ele seja mantido.

Há três correntes sobre o pleno emprego:

a. keynesiana: demanda de trabalho é insuficiente;

b. funcionamento do mercado, que impõe o preço do trabalho;

c. marco regulatório: instituições e legislação impõem desemprego.

Políticas ativas são os serviços de pleno emprego, treinamento, apoio aos jovens, subsídios, assistência à procura do trabalho, auxílio para negócio próprio.

Políticas passivas são o seguro-desemprego, suspensão para qualificação profissional (art. 476-A da CLT) ou outros benefícios, aposentadoria precoce ou incentivo à aposentadoria para gerar novos empregos, de reduzir o desemprego é estimular as aposentadorias.

Administração de Empresas

8. A Administração de Empresas se preocupa com a organização da empresa, sua forma de produção. Vai estabelecer quantos funcionários necessita, cargos, salários etc.

A organização da empresa implica o exercício do poder de organização da empresa, que está incluído no poder de direção do empregador.

Uma das partes da Administração de Empresas é a Administração de Recursos Humanos, que estuda a estrutura de retribuições no mercado de trabalho.

Os recurso humanos estão divididos em direção, no nível intermediário (gerência e assessoria), no nível operacional (técnicos, funcionários e operários).

A teoria do comportamento humano é indicada por Douglas McGregor, que desenvolve a Teoria $\mathrm{X}$ e a Teoria Y. Na primeira, o ser humano não gosta de 
trabalho e o evitará. Na segunda, o trabalho pode ser uma fonte de satisfação ou de sofrimento, dependendo das condições controláveis.

William Ouchi desenvolve a Teoria $Z$, tratando da concepção japonesa de administração. A produtividade seria a administração de pessoas, muito mais do que tecnologia. O gerenciamento humano é fundamentado na filosofia e cultura organizacionais adequadas do que de tratamentos tradicionais fundados na organização. O processo decisório é participativo e consensual.

A participação na gestão tem relação com a Administração de Empresas, pois será a forma de gerir a empresa juntamente com os empregados. Tem previsão o tema no inciso XI do artigo $7 .^{\circ}$ da Constituição e no art. 621 da CLT, que permite que a participação seja estabelecida por convenção ou acordo coletivo. Até o momento não foi disciplinada por meio de lei.

Os Recursos Humanos envolvem recrutamento, técnicas de recrutamento, critérios de seleção de pessoal. A movimentação interna dos recursos humanos, como as promoções, os planos de cargos e salários, remuneração indireta dos participantes, visando inclusive a produtividade, benefícios sociais que podem ser concedidos, motivação da força de trabalho, ambiente de trabalho agradável, inclusive quanto a segurança e higiene do trabalho, estudo relativo à rotação de pessoal ou turnover. Muito se fala nas dispensas dos trabalhadores que já estão treinados na empresa e que acabam indo para o concorrente. Há, portanto, necessidade de manter esses trabalhadores na empresa. É preciso identificar por que existe rotatividade de pessoal na empresa, que pode ser decorrente de vários fatores.

Contabilidade

9. A relação do Direito do Trabalho com a Contabilidade diz respeito aos cálculos das verbas trabalhistas, à escrituração das contas das empresas, podendo ser verificados o pagamento dos salários e de outras verbas aos empregados.

A Contabilidade aplica o Direito do Trabalho na elaboração de folha de pagamentos, na observância de pagamentos aos empregados e recolhimentos do FGTS nos prazos definidos na lei.

\section{Estatística}

10. Não havia preocupação sobre tal aspecto no Direito.

O professor Pastore mostra nos seus livros a importância da utilização de 
dados estatísticos no mundo do trabalho, inclusive para justificar seus pontos de vista. São importantes dados estatísticos os relativos à evolução do desemprego, da demanda e oferta de trabalho, do salário mínimo, do custo da subsistência.

Medicina

11. A Medicina do Trabalho é uma das espécies da Medicina.

Estudos importantes sobre a prevenção e reparação da saúde do trabalhador foram feitos por Bernardino Ramazzini, na Itália, na cidade de Módena, em 1700. Escreveu o livro As doenças dos trabalhadores. O referido trabalho foi considerado o texto básico da Medicina Preventiva até por volta do século XIX. São dele os aforismos "mais vale prevenir do que remediar" e "todo trabalho torna-se perigoso se praticado em excesso"

Na CLT há o capítulo sobre segurança e medicina do trabalho, conforme os arts. 154 a 201 da CLT, na redação determinada pela Lei n. 6.514/77.

Os citados artigos são complementados pela NR 15 da Portaria n. 3.214/ 78 , que indica elementos químicos, físicos ou biológicos que trazem malefícios à saúde do trabalhador e que são analisados pela Medicina do Trabalho para efeito do trabalho insalubre.

Durante o trabalho são produzidas substâncias nocivas, como o ácido lático e o ácido carbônico. Quando essas substâncias se acumulam no organismo há a fadiga.

Preocupa-se a Medicina do Trabalho com a saúde dos trabalhadores. Pretende limitar a jornada de trabalho para evitar a fadiga. Estabelece intervalos, descansos semanais, férias e medidas preventivas em relação a acidentes do trabalho. A redução da jornada em trabalho insalubre e o aumento de dias de férias nesse mister são recomendados na Medicina do Trabalho.

A Medicina pode ser importante fundamento para verificar seguros de enfermidade, de maternidade, de situações de trabalho insalubre.

Psicologia

12. A Psicologia do Trabalho é uma parte da Psicologia. É o estudo das técnicas para adaptação do trabalhador à sua atividade.

O trabalho é um comportamento para o psicólogo.

A tecnopsicologia estuda a maneira de trabalhar.

As relações entre empregado e empregador dizem respeito à psicologia social ou econômica. 
A Psicologia vai estudar não só a adaptação do homem ao trabalho, mas também do trabalho ao homem. Analisa os processos em que se divide a atividade humana para então utilizar os conhecimentos da psicologia, conforme as reações das pessoas.

A adaptação do homem ao trabalho envolve a seleção e a formação profissional. Vai estudar os movimentos profissionais, o ambiente de trabalho, inclusive as instalações, máquinas e utensílios.

O trabalhador contribui para o funcionamento da estrutura da empresa.

É campo de trabalho o estudo das interações entre o homem, os instrumentos de trabalho e o ambiente técnico.

Os testes psicotécnicos são feitos pelo psicólogo, visando o recrutamento do trabalhador. Muitas vezes em testes de seleção é usada a dinâmica de grupo para verificar como a pessoa se sai em situações grupais.

A seleção procura escolher as pessoas com as aptidões necessárias para o trabalho. O psicólogo do trabalho pode ter o interesse de aumentar o rendimento do trabalhador e sua satisfação pessoal no trabalho. Isso pode evitar prejuízos no trabalho.

A psicologia pode estudar o trabalho de forma a que dê maior rendimento, de forma que o trabalhador preste serviços na posição mais conveniente. As máquinas também deveriam levar em conta quem irá operá-las, sob o aspecto do operador.

$\mathrm{O}$ trabalho deve ser adaptado ao homem e não o contrário. Assim como a máquina deve ser adaptada ao homem e não este à máquina, principalmente tomando por base as questões relativas à fadiga, do ritmo de trabalho e do repouso.

O tempo pode trazer pressões sobre o trabalho. A decisão e a satisfação também devem ser estudados no trabalho, o que é feito pelo psicólogo.

A Psicologia pode estudar o caráter, os gostos, as tendências do trabalhador para o trabalho na empresa. Vê o esforço do trabalhador para produzir.

O estudo da ergonomia também é feito pelo psicólogo do trabalho, no sentido de verificar a adaptação do homem ao trabalho e vice-versa. A NR 17 da Portaria n. 3.214/78 trata da ergonomia no trabalho, como de iluminação, postura no trabalho etc.

O psicólogo do trabalho pode tentar melhorar a segurança no trabalho, diminuir a carga do trabalho, tentar reduzir o absenteísmo, aumentar o grau de satisfação.

A Psicologia se preocupa também com os estudos das causas e efeitos da fadiga.

Filosofia do Trabalho

13. Uma das partes da Filosofia é a Filosofia do Trabalho. 
Há pelo menos dois estudos importantes sobre o tema Filosofia do trabalho, de Felice Battaglia e Filosofia do trabalho de Luigi Bagolini.

$\mathrm{Na}$ Bíblia o trabalho foi considerado um castigo por Adão ter comido a maçã. Adão e Eva foram expulsos do Paraíso. Deus disse que "do suor do teu rosto comerás o teu pão" Cristo libertou o mundo do pecado original. Assim, mediante o trabalho, o homem modela o mundo à imagem e semelhança de Deus. Trabalho também seria a criação do bem comum.

Homero afirma que os deuses odeiam os homens e precisamente aparece o trabalho como consequiência deste ódio. Xenofonte diz que "o trabalho é a retribuiçũo da dor mediante a qual os deuses nos vendem os bens" Pródico alega que o trabalho confere dignidade à vida.

Os gregos afirmavam que o trabalho era o castigo dos deuses. Os nobres não trabalhavam. Mencionava Aristóteles que "a escravidão de uns é necessária para que outros possam ser virtuosos". O trabalho impediria o homem de atingir a perfeição. Platão asseverava que "os trabalhadores da terra e os outros operários conhecem só as coisas do corpo; se, pois, sabedoria implica conhecimento de si mesmo, nenhum destes é sábio em função da sua arte"

Os sofistas tinham entendimento diverso. Para Pródico, "nada do que é bom e belo concederam os deuses ao homem sem esforço e sem estudo; se queres que a terra te produza frutos abundantes, deves cultivá-la"

No Renascimento, a consciência do trabalho era considerada como um valor. Smith entendia que a riqueza era o resultado do trabalho. Palmieri menciona que a riqueza das nações é a soma dos trabalhos nelas executados. São Tomás de Aquino leciona, ao interpretar a Bíblia, que antes do pecado teria havido trabalho para o homem, mas ele teria sido delitoso e sem pena, deleitoso pelo sentimento que o acompanhava, sendo atividade para a qual os homens eram dispostos por divina providência, pela virtude que havia nas almas, integral e sem falácia. Para Hegel, o trabalho é o próprio meio de o homem encontrar-se.

Trabalho é um valor na ordem ético-jurídica conferido ao homem.

Leão XIII afirma que o "trabalho é a atividade humana ordenada para prover às necessidades da vida, e especialmente à sua conservação". A Constituição de 1924 previa que "quem trabalha não come" No preâmbulo da Constituição francesa de 1946 está escrito: "todos têm o dever de trabalhar e o direito de obter emprego"

$\mathrm{O}$ trabalho é um direito da pessoa. É uma atividade lícita. O direito ao trabalho é uma forma de dignidade da pessoa e da independência como homem. $\mathrm{O}$ 
homem deve ser tratado como pessoa e não como coisa. O inciso III do art. $1^{\circ}$ da Constituição consagra a dignidade da pessoa humana. É um direito social (art. $6^{\circ} \mathrm{da}$ Constituição).

Um dos fins do Estado é assegurar as condições necessárias para que as pessoas se tornem dignas. O homem se realiza por intermédio do trabalho. Precisa do trabalho para poder viver. $O$ direito ao trabalho é um dever que deveria ser exigido do Estado. A existência digna do homem implica o direito ao trabalho, para que possa existir. Deve ser proporcionado trabalho ao homem.

O direito ao trabalho tem como conseqüencia do dever de trabalhar se há trabalho. $\mathrm{O}$ direito ao trabalho seria uma liberdade pública. Entretanto, seria liberdade pública se o trabalhador pudesse ir a juízo e exigir do Estado o direito de trabalhar. É o direito que todo homem tem de viver, proporcionando-se, pelo próprio trabalho, os recursos necessários.

Não pode haver uma intervenção excessiva do Estado na relação de trabalho, sob pena de destruir a liberdade das pessoas de contratarem, importando até em servidão pública.

O trabalho, porém, não pode ser considerado como mera mercadoria. Afirma José Cretella Jr. que não basta viver. É preciso viver com dignidade. A valorização do trabalho é pressuposto da existência digna. Com o trabalho se atinge a essência. $O$ trabalhador deveria ter o direito de continuar trabalhando, da continuidade do contrato de trabalho. Com o trabalho, poderá ter existência digna.

São Paulo, julho de 2003. 